CASE REPORT

\title{
Hemorrhagic Fevers with Renal Syndrome Presenting with Pregnancy Interruption
}

\author{
Elda Qyra ${ }^{1}$, Edmond Puca ${ }^{1}$, Arjan Harxhi ${ }^{1}$, Majlinda Kote ${ }^{2}$, Pellumb Pipero ${ }^{1}$ \\ ${ }^{1}$ University Hospital Center of "Mother Theresa", Department of infectious Diseases, Tirana, Albania \\ ${ }^{2}$ Institute of Public Health, Tirana, Albania
}

\begin{abstract}
Hemorrhagic fever with renal syndrome is presented with so many different clinical symptoms. It can present mild form of the disease or the severe symptoms. We reported two cases with HFRS, at pregnant women, ended with pregnancy interruption. Both of them had nearly the same age, both 16 weeks pregnant. They presented with fever, malaise, muscle pain and headache. They were febrile when presented at the hospital, hypotensive, hyperemia on the face. They complained about oligo-anuria too. One of them continued to be hypotension, despite the supportive therapy she had an abortion after 8 hours. The other patient had the abortion on the $4^{\text {th }}$ day of hospitalization. The diagnose was set based on the clinical, epidemiological findings and the serological positive confirmation for IgM Hantavirus by enzyme-linked immunosorbent assay and immunofluorescence assay IFA.

The abortion is a rare complication of HFRS in pregnancy. The symptoms are not specific. Early diagnosis and appropriate management are necessary to improve the maternal and fetal outcome. J Microbiol Infect Dis 2017; 7(4):198-201
\end{abstract}

Keywords: Hemorrhagic fever with renal syndrome, pregnancy, interruption

\section{INTRODUCTION}

Hantaviruses can cause potentially fatal diseases in humans, such as Hantavirus Hemorrhagic Fever with Renal Syndrome (HFRS) and Hantavirus Pulmonary Syndrome (HPS) also known as Hantavirus Cardiopulmonary Syndrome (HCPS). Hantaviruses are negative-sense RNA viruses that belong to the Bunyaviridae family [1-3]. Epidemiologically HFRS is a rare disease in Albania, but time after time there are cases reported [4]. In Kosovo, our neighbor country, the disease is more spread, often with small outbreaks [5]. Clinically, it can present the mild form of the disease, sometimes undiagnosed, to the most severe symptoms. It can manifest an acute high fever, thrombocytopenia and renal failure. Beside the classic forms with the involvement of the kidneys, sometimes this disease can be complicated including even other organs $[4,6]$. But, on the other hand it can be fatal for the fetus in pregnant women [7]. Hantavirus infection during pregnancy can influence both maternal and fetal outcomes. Although rare even in endemic areas, different Hantavirus strains infection in pregnant women had been reported, which has a different influence on the maternal and fetal outcomes [8]. In this presentation, we want to present the cases of two pregnant women at the same age of pregnancy, living at the same place and infected during their farm work. There are some cases, in literature, presenting HFRS with pregnancy interruption, but there is not a genuine study about it.

\section{CASE}

There are two women patients, cousins, living at the same house, presented to the Regional Hospital of Kukes with fever, chills and malaise. The symptoms first showed up 2-3 days before. Epidemiologically, they did farm work and this time they bought the food for their livestock in our neighbor country, Kosovo. This country is well known for infections from Hantavirus and reported cases with HFRS [8]. Inside the grass 
bundles were found pieces of animals (fur, bones). The patients were presented at our hospital with fever, chills, malaise and one of them had hemorrhagic lesions (hematoma) on both arms. They were both pregnant, as well.

The first patient continued to be hypotensive regardless to the supportive therapy and after 8 hours from admission she complained abdominal pain, hemorrhagic amniotic fluid and then she had the abortion (assisted by the gynecologist). This was the first pregnancy for her and her doctor didn't notice any problem until now. The second patient had the abortion on the 4th day of hospitalization. This was her $2^{\text {nd }}$ pregnancy and she had no problem with the first one. They were tested for HFRS and other pathologies similar to it. The tests were negative for leptospirosis, toxoplasmosis, viral hepatitis, and herpes simplex viruses, cytomegalovirus and Epstein-Barr virus infection. Acute phase sample was positive for Hantavirus $\lg \mathrm{M}$ by enzyme-linked immunosorbent assay (ELISA) and immunofluorescence assay IFA (HTNV,) but negative for anti-hantavirus IgG antibodies. Convalescent sample of the patient showed high levels of anti-hantavirus IgG both by ELISA.

Table 1. Clinical presentation of the patients.

\begin{tabular}{lcc}
\hline Variables & Patient 1 & Patient 2 \\
\hline Age (in years) & 36 & 38 \\
Pregnancy duration (week) & 16.1 & 16.5 \\
Temperature & + & + \\
Hypotension & + & + \\
Oliguria & + & + \\
Hematoma & + & - \\
Rectorrhagia & - & - \\
Metrorrhagia & + & - \\
Cephale & + & + \\
Mialgya & + & + \\
Lumbalgya & + & + \\
Abdominal cramp & + & + \\
\hline
\end{tabular}

Table 2. Laboratory examination of the patients.

\begin{tabular}{lcccc}
\hline Parameters & Unit & Normal range & Patient 1 & Patient 2 \\
\hline White blood cells & $106 / \mathrm{mm} 3$ & $4-10$ & 5.6 & 2.1 \\
Red blood cell counts & $106 / \mathrm{mm} 3$ & $4.20-6.10$ & 2.65 & 3.47 \\
Haemoglobin & $\mathrm{g} / \mathrm{dl}$ & $11-16.5$ & 7.9 & 10.1 \\
Platelets & $103 / \mathrm{mm} 3$ & $150-450$ & 13.0 & 75.0 \\
Glicemia & $\mathrm{mg} / \mathrm{dL}$ & $74-106$ & 134 & 75 \\
Blod urea nitrogen & $\mathrm{mg} / \mathrm{dL}$ & $10-43$ & 93 & 153 \\
Creatinine & $\mathrm{mg} / \mathrm{dL}$ & $0.7-1.4$ & 2.3 & 1.5 \\
Aspartate aminotransferase & $\mathrm{U} / \mathrm{L}$ & $0-35$ & 61 & 157 \\
Alanine transaminase & $\mathrm{U} / \mathrm{L}$ & $0-45$ & 30 & 68 \\
Creatine phosphokinase & $\mathrm{U} / \mathrm{L}$ & $0-171$ & 32 & 34 \\
Gammaglutamyltransferase & $\mathrm{U} / \mathrm{L}$ & $0-55$ & 42 & 38 \\
Bilirubin & $\mathrm{U} / \mathrm{L}$ & $0.3-1.2$ & 2.8 & 2.2 \\
Albumin & $\mathrm{g} / \mathrm{dL}$ & $3.5-5.2$ & 3.3 & 2.2 \\
Total protein & $\mathrm{g} / \mathrm{dL}$ & $6.0-8.3$ & 5.9 & 5.7 \\
Fibrinogen & $\mathrm{mg} / \mathrm{dL}$ & $169-515$ & 78 & 284 \\
\hline
\end{tabular}

\section{DISCUSSION}

Hemorrhagic fever with renal syndrome is a disease caused by Hantaviruses. It is now a well-known disease in Albania and Kosovo [4,5]. It has the highest incidence in Kosovo [5]. Humans may become infected with hantaviruses through contact with rodent urine, saliva, or feces. In our case it was transmitted by the bones and the fur found in the grass. The food was taken in Kosovo, where the infection from hantavirus is often reported. Its clinical forms are very different. Reports of cases of pregnancy complicated by hantavirus infection are scarce, but they reported in the literature $[6,7,9]$. In
Albania, there are cases reported since 1986, but this is the first presentation when HFRS is complicated with two pregnant women at the same time. We were confused because distinguishing between hantan infection and certain liver pathologies of pregnancy, especially severe preeclampsia with haemolysis, elevated liver enzymes and low platelet count (HELLP) syndrome and AFLP was problematic. Such syndromes have been suspected in pregnant women infected with Hantaviruses. They were previously healthy, without any recorded complications during their pregnancies prior to the HFRS diagnosis. Some reports were 
published in the available literature describing PUUV, DOBV, Sin Nombre Virus, Hantaan virus (HTNV), and undifferentiated Hantavirus infections in pregnancy [8]. Cases of maternal infection are described in China and Korea. Host- and virus-specific factors are considered to contribute to the severity of the disease. Routine Hantavirus diagnosis in Albania is based on commercial serological assays that do not allow discrimination between different hantavirus infections, and consequently diagnosed infections are mostly attributed to DOB virus infection, the main prevalent hantavirus in Balkan. Based on serological tests by Institute of Public Health and other publication DOBV is the causative agent for HFRS in Albania $[2,10]$. The diagnosis is based on the clinical findings and can be confirmed serologically. Even if the woman recovers completely, there is no certainty if the infection is harmful to the fetus or not. Unfortunately, we couldn't test the fetus for HFRS, IgG and IgMantibodies, as well as HTNV-RNA, and it was not clear for us to know whether we had a transplacental transmission of infection or not. Anyway, these cases sustain the literature data that the Hantaviruses have a high risk for transplacental transmission [7]. According to our data and experience we had cases with pancreatitis, orchitis but it is the first case with pregnancy interruption [4,11]. It is not completely clear what kind of physiological changes had happened in our cases to contribute to the interruption of pregnancy. With the first patient, who was the first losing her baby, we noticed that she had hypotension and very low levels of fibrinogen [12]. Maybe low levels of fibrinogen are prognostic factors, especially in hemorrhagic fever of Crime-Congo [13].

\section{Conclusions}

Based on the phispathology of HFRS, it is an interesting disease with lots of complications. Regardless of the pregnancy interruption, it is a rare complication of HFRS, but the total number of Hantavirus infections in Europe is increasing last years and physicians will be faced prospectively with a higher number of infections in pregnancy. In areas where it occurs, HFRS should be considered in the differential diagnosis of acute febrile illnesses during pregnancy.

\section{ACKNOWLEDGMENTS}

Conflict of interest: The authors declare no personal or financial conflict of interest.

Funding disclosure: Non to declare

\section{REFERENCES}

1. Berk $\mathrm{H}$, Öztoprak N. Hemorrhagic fever with renal syndrome (Hantaviruses). J Microbiol Infect Dis 2014, 4(5).

2. Županc TA, Korva M, Markotić A. HFRS and hantaviruses in the Balkans/South-East Europe. Virus Research 2014, 187:27-33.

3. Kostakoglu U, Yılmaz G, Volkan S, Sökel SK, Kaya S, Köksal I. Evaluation of clinical and laboratory predictors of fatality in patients with Hantavirus infection. J Microbiol Infect Dis 2012, 2(04).

4. Puca E, Pilaca A, Pipero P, et al. A short review of hemorrhagic fever with renal syndrome and it's extrarenal complications. J Microbiol Infect Dis 2014, 4(5).

5. Emmerich $P$, Müller $N$, Heinemann $P$, et al Human Dobrava-Belgrade hantavirus infection, Kosovo. J Clin Virol 2014, 61(3):439-441.

6. Mustonen J, Vaheri A, Clement J. Third international conference on haemorrhagic fever with renal syndrome (HFRS) and hantaviruses. Nephrology Dialysis Transplantation 1996, 11(4):730-733.

7. Kim B-N, Choi B-D. Hemorrhagic fever with renal syndrome complicated with pregnancy: a case report. The Korean journal of internal medicine 2006, 21(2):150.

8. Hofmann J, Führer A, Bolz M, et al. Hantavirus infections by Puumala or Dobrava-Belgrade virus in pregnant women. Journal of Clinical Virology 2012, 55(3):266-269.

9. Howard MJ, Doyle TJ, Koster FT, et al. Hantavirus pulmonary syndrome in pregnancy. Clin Infect Dis 1999, 29(6):1538-1544.

10. Rogozi E, Bego F, Papa A, Mersini K, Bino S. Distribution and ecology of small mammals in Albania. International journal of environmental health research 2013, 23(3):258-268.

11. Puca E, Pilaca A, Pipero $P$, et al. Hemorrhagic fever with renal syndrome complicated by orchitis. Virologica Sinica 2011, 26(4):285.

12. Du H, Li J, Yu H-T, et al. Early indicators of severity and construction of a risk model for prognosis based upon laboratory parameters in patients with hemorrhagic fever with renal 
syndrome. Clinical Chemistry and Laboratory Medicine (CCLM) 2014, 52(11):1667-1675.

13. Ozturk B, Tutuncu E, Kuscu F, Gurbuz Y, Sencan I, Tuzun $H$. Evaluation of factors predictive of the prognosis in Crimean-Congo hemorrhagic fever: new suggestions. Int J Infect Dis 2012, 16(2):e89e93. 